Lepr Rev (1989) 60, 263-266

\title{
Primary dapsone resistance in China
}

\author{
CHEN JIA-KUN, WANG SI-YU, HOU YU-HONG, \\ NI GUO-XING, ZHANG JIA-LIN \& \\ TANG QUAN-GUI \\ Zeng Yi Hospital, Shanghai, China
}

Accepted for publication 22 May 1989

\begin{abstract}
Summary Ninety-seven strains of Mycobacterium leprae recovered from patients with previously untreated multibacillary leprosy were tested for dapsone susceptibility. The specimens originated from Shanghai Municipality, Jiang-su Province and Fu-jian Province. Approximately $28 \%$ of the strains either did not infect the mice or the results of susceptibility were inconclusive due to the low proportion of viable organisms in the bacterial populations. Among the 70 strains in which dapsone susceptibility could be tested in mice, $31(44 \%)$ strains were found with primary dapsone resistance. Although the majority of the primary dapsone resistant strains were shown to be of a low- or intermediate-degree, onesixth of them were of high-degree resistance.
\end{abstract}

\section{Introduction}

In order to assess the severity of the problem of dapsone resistant leprosy in China, where dapsone monotherapy has been widely used for the treatment of leprosy since the beginning of the 1950s, surveys of secondary and primary dapsone resistance in China were undertaken according to the THELEP Protocol for Surveys of Dapsone Resistance. ${ }^{1}$ The results of the survey of secondary dapsone resistance in Shanghai Municipality have already been published. ${ }^{2}$ The survey on primary dapsone resistance was conducted between 1982 and 1986 and its preliminary results have been presented in a review article. ${ }^{3}$ The complete information from the survey is now available.

\section{Materials and methods}

For the study of primary dapsone resistance, only previously untreated multibacillary (MB) leprosy patients with bacterial index $(\mathrm{BI}) \geq 3$ in at least one lesion should be included. Since the incidence rate of leprosy has become very low in most parts of China, in order to accumulate more convincing data, we also obtained random specimens from nearby provinces including Jiang-su, Fujian and An-hui in addition to virtually all the newly detected MB cases from Shanghai Municipality. During the study period, 97 skin biopsies from previously untreated MB patients were collected: 16 from Shanghai Municipality, 44 from Jiang-su Province, 34 from Fu-jing Province and 3 from An-hui 
Province. Of the 97 cases, 78 were male and 19 female; 47 were LL, 6 LL/BL, 37 BL, 5 BB and 2 BB/ BT: ages ranged from 12 to 74 with a median of 31 .

The dapsone-susceptibility tests were carried out following the standard technique. ${ }^{4}$ In brief, as soon as the specimens arrived at our Leprosy Research Laboratory, they were homogenized, and the $M$. leprae were recovered, counted, diluted so as to provide an inoculum of $10^{4}$ organisms per footpad, and inoculated into both hind footpads of 40-60 outbreed Swiss albino mice per specimen. One group of 10-20 mice were administered a drug-free diet, and three additional groups were fed diets into which dapsone had been incorporated in concentrations of $0.0001,0.001$ or $0.01 \mathrm{~g}$ respectively per $100 \mathrm{~g}$ diet. Six months after inoculation, $M$. leprae was harvested from the inoculated footpads of two to four untreated mice and pools of both hind footpads from each mouse counted. This was repeated at intervals of about two months, until the average number of organisms per footpad was found to be at least $5 \times 10^{5}$. At this time, harvests of $M$. leprae were perf ormed on the inoculated footpads of the remaining control mice and all treated mice. If af ter 12 months the organisms were found to have multiplied in the control mice, but to an average of fewer than $5 \times 10^{5}$ organisms per footpad, harvests were also performed on both the control and the treated mice. Multiplication of $M$. leprae was judged to have taken place when they had increased to $\geq 10^{5}$ per footpad. Using this criterion, the results of the susceptibility test were interpreted as follows: (a) non-infective in mice-no multiplication was observed in a single control mouse; (b) inconclusive - although no multiplication was observed in the treated mice, multiplication occurred in so few of the control mice that one could not distinguish the number of control mice demonstrating multiplication from zero; (c) susceptible-multiplication of $M$. leprae was observed only in untreated mice but not in treated mice; (d) resistant - the organisms were observed to have multiplied in at least one drug-treated mouse. The degree of resistance was determined by the diet containing the largest concentration of dapsone that permitted multiplication of $M$. leprae, and was then defined as low, intermediate or high, depending on the ability of the organisms to multiply in mice which had been administered dapsone in concentrations of, respectively, $0.0001,0.001$ or $0.01 \mathrm{~g}$ per $100 \mathrm{~g}$ diet.

\section{Results}

The results of the study are presented in Table 1. Out of 97 specimens, the organisms from 14 of them did not infect mice; and the results from 11 specimens were inconclusive because multiplication of $M$. leprae was observed in only a very few control mice. Obviously, the proportion of viable organisms in the bacterial populations of these specimens was too small. In addition, the results of another two specimens were also considered to be inconclusive because the mice administered the $0.0001 \mathrm{~g} \%$ dapsone diet were lost before harvest, whereas no multiplication was

Table 1. Results of dapsone-susceptibility test among 97 untreated multibacillary leprosy patients in China

\begin{tabular}{lr} 
Non-infective in mice & 14 \\
Inconclusive due to low-infectivity & 11 \\
Inconclusive due to loss of mice administered & \\
dapsone in smallest concentration & 2 \\
Susceptible & 39 \\
Resistant & 31 \\
$0.0001 \mathrm{~g} \%$ & 16 \\
$0.001 \% \mathrm{~g} \%$ & 10 \\
$0.01 \mathrm{~g} \%$ & 5 \\
\hline
\end{tabular}


Table 2. Comparison of the results of dapsone-susceptibility test among untreated multibacillary leprosy patients in three different areas in China

\begin{tabular}{lcrr}
\hline Results & Shanghai & Jiang-su & Fu-jian \\
\hline Susceptible & $6(50 \%)$ & $15(43 \%)$ & $18(78 \%)$ \\
Resistant & $6(50 \%)$ & $20(57 \%)$ & $5(22 \%)$ \\
\hline
\end{tabular}

observed in treated mice which had been administered higher concentrations of dapsone in their diet. Therefore, it was possible to assess the susceptibility to dapsone of the $M$. leprae recovered from 70 specimens.

Of the 70 specimens, $M$. leprae recovered from 39 of them were judged to be dapsone susceptible and the remaining 31 strains were dapsone resistant. Therefore, the prevalence of primary dapsone resistance was found to be $44 \%$. Regarding the degree of dapsone resistance among the 31 resistant strains, $16(52 \%)$ were low-degree, $10(32 \%)$ were intermediate-degree and $5(16 \%)$ were highdegree. Although the first two categories were in the majority, it should be noted that close to onesixth of the primary resistant strains were of high-degree dapsone resistance.

Table 2 compares the results of dapsone-susceptibility tests among untreated MB leprosy patients from three different areas in China. It appears that the prevalence of primary dapsone resistant leprosy in Fujian Province $(22 \%)$ was significantly lower $(P<0.05)$ than that in Jiang-su Province $(57 \%)$. However, the differences between Shanghai and either Jiang-su Province or Fujian province were not statistically significant $(P>0 \cdot 05)$.

\section{Discussion}

Prior to 1977 , dapsone susceptibility of 73 strains of $M$. leprae recovered from patients with previously untreated lepromatous leprosy had been tested in six laboratories including our laboratory, but none of the strains was resistant to dapsone. ${ }^{5}$ However, since primary dapsoneresistant leprosy was first reported from Ethiopia in $1977,{ }^{6}$ the prevalence of primary dapsoneresistant leprosy has reached an alarming level. Prior to the current study, there have been only two other reports of extensive investigations of primary dapsone resistance. In the study carried out with specimens obtained from Bamako and Chingleput in India, 37\% of the 131 patients harboured strains with primary resistance to dapsone, ${ }^{7}$ in the other study, in which biopsies were received from Guadeloupe, Martinique, New Caledonia, Senegal and Paris, $39 \%$ of the 133 patients were infected with primary dapsone resistant $M$. leprae ${ }^{8}$ Not only were both studies conducted at almost the same period of time as ours, but the prevalence of primary dapsone resistance from both studies was also very similar to those in the current report. Thus, there is no doubt that primary dapsone resistant leprosy had become a worldwide phenomenon by the early 1980s.

In contrast to secondary dapsone resistant leprosy, ${ }^{2,3}$ the majority of primary resistant strains of $M$. leprae were resistant to low or intermediate levels of dapsone. The explanation for this difference may lie in the long incubation period of MB leprosy. It is possible that most patients recognized today as having primary resistance were infected 10 or more years ago, at which time the degree of dapsone-resistance among most secondary resistant strains may have been much lower than that of today. If this is the case, one may anticipate that future primary dapsone-resistant strains will manifest higher degrees of resistance than those encountered at present. In fact, high-degree dapsone resistance did occur in some previously untreated patients as is shown in the current report and also in the literature. ${ }^{8}$ 
Since secondary and primary dapsone-resistant strains of $M$. leprae have been found wherever they were sought, there is clearly an urgent need for all leprosy control programmes to implement the multidrug regimens recommended for paucibacillary and multibacillary leprosy by the WHO Study Group. ${ }^{9}$

\section{Acknowledgment}

This investigation received financial support from the UNDP/World Bank/WHO Special Programme for Research and Training in Tropical Diseases.

\section{References}

${ }^{1}$ Subcommittee on Dapsone Resistance Surveys of the Steering Committee of the Chemotherapy of Leprosy (THELEP). Protocol for surveys of dapsone resistance. TDR/THELEP/PRT/78·1.

2 Ji B, Chen J, Zhang J, Hou Y, Ni G, Zhang R. Secondary dapsone-resistant leprosy in Shanghai Municipality. Lepr Rev, 1983; 54: 197-202.

3 Ji B. Drug resistance in leprosy-A review. Lepr Rev 1985; 56: 262-78.

${ }^{4} \mathrm{Ji}$ B. Drug susceptibility testing of Mycobacterium leprae. Int J Lepr, 1987; 55 (Suppl,): 830-5.

${ }^{5}$ Shepard CC, Rees RJW, Levy L, Pattyn SR, Ji B, Dela Cruz EC. Susceptibility of strains of Mycobacterium leprae isolated prior to 1977 from patients with previously untreated lepromatous leprosy. Int J Lepr, 1986; 54: 11-15.

${ }^{6}$ Pearson JMH, Haile GS, Rees RJW. Primary dapsone-resistant leprosy. Lepr Rev, 1977; 48: 129-32.

7 Subcommittee on Clinical Trials of the Chemotherapy of Leprosy (THELEP) Scientific Working Group of the UNDP/World Bank/WHO Special Programme for Research and Training in Tropical Diseases. Primary dapsone resistance in Bamako and Chingleput: Final report. Lepr Rev, 1987, 58: 209-18.

${ }^{8}$ Guelpa-Lauras CC, Cartel J, Constant-Desportes M, Millian J, Robin P, Guidi C, Brucker G, Flageul B, Guillaume J, Pichet, C, Remy J, Grosset JH. Primary and secondary dapsone resistance of M. leprae in Martinique, Guadeloupe, New Caledonia, Tahiti, Senegal, and Paris between 1980 and 1985. Int J Lepr, 1987, 55: 672-9.

9 WHO Study Group. Chemotherapy of leprosy for control programmes. Technical Report Series No. 675. WHO: Geneva, 1982. 